\title{
Necesidades de agua de riego en una explotación comercial de almendro mediante teledetección
}

\author{
Pérez García, Yeray ${ }^{1}$, Campoy Urrea, Jaime ${ }^{1}$, Calera Belmonte, Alfonso ${ }^{1}$ \\ Grupo de Teledetección y SIG. Instituto de Desarrollo Regional. Universidad de Castilla-La Mancha. Campus Universitario SN. Albacete \\ (España); Yeray.Perez@alu.uclm.es; Jaime.Campoy@uclm.es; Alfonso.Calera@uclm.es
}

\section{Resumen:}

La superficie dedicada al cultivo del almendro (Prunus dulcis) en regadío se ha duplicado en España en los últimos 5 años. La alta respuesta del rendimiento de este cultivo a la cantidad de agua aplicada junto con su elevada rentabilidad ha propiciado que actualmente el cultivo del almendro se convierta en una alternativa al cultivo de cereales y otros leñosos en muchas zonas del territorio nacional. No obstante, la expansión del cultivo en zonas con escasez de agua hace necesario el desarrollo y la aplicación de herramientas que permitan conocer sus necesidades de agua con la suficiente precisión, resolución espacial y temporal, con el objetivo de optimizar los recursos hídricos, realizar una gestión más rentable y sostenible con el entorno. De esta manera, las series temporales de imágenes de NDVI de satélite surgen como una herramienta valiosa que permiten caracterizar la evolución espacial y temporal de la cubierta vegetal y estimar con precisión la evolución del coeficiente de cultivo a lo largo del ciclo de crecimiento siguiendo las relaciones establecidas en la literatura científica.

El objetivo del presente estudio es determinar la evapotranspiración del cultivo del almendro y sus necesidades de agua de riego a través de la implementación del modelo de balance diario de agua en el suelo explorado por las raíces descrito en el manual de FAO 56 y asistido por teledetección. La metodología propuesta integra el coeficiente basal de cultivo $\left(\mathrm{K}_{\mathrm{cb}}\right)$ derivado de la serie temporal de imágenes de satélite en el balance de agua. Dicha metodología está bien documentada en la literatura científica para otros cultivos, aunque permanece casi inexplorada y con escasa experiencia previa para el cultivo del almendro.

El estudio se ha realizado en una explotación de almendro con riego localizado situada en el término municipal de Abarán (provincia de Murcia) durante la campaña 2019. Las necesidades de agua de riego estimadas con el modelo propuesto son evaluadas frente a datos reales de riego aplicados por el agricultor.

Los resultados obtenidos revelan el desempeño de la metodología propuesta para estimar con precisión las necesidades de agua de riego del cultivo del almendro a lo largo de la campaña de estudio, capturando diferencias en los requerimientos de agua del cultivo entre las parcelas analizadas. La aplicación de la metodología en situaciones reales permite al agricultor ajustar el suministro de agua a las demandas del cultivo, y ampliar su conocimiento sobre el uso del agua realizado en la explotación. Esta información resulta de gran utilidad para la toma de decisiones orientadas a la mejora de la planificación de riegos, elaboración de estrategias de riego deficitario controlado (RDC) y a una optimización de la gestión y uso de los recursos hídricos.

Palabras clave: NDVI ; almendro ; regadío ; satélite ; coeficiente de cultivo ; evapotranspiración 


\title{
Irrigation water requirements in an almond commercial farm using a remote sensing-based approach
}

\author{
Pérez García, Yeray ${ }^{1}$, Campoy Urrea, Jaime ${ }^{1}$, Calera Belmonte, Alfonso ${ }^{1}$
}

1 Grupo de Teledetección y SIG. Instituto de Desarrollo Regional. Universidad de Castilla-La Mancha. Campus Universitario SN. Albacete (España); Yeray.Perez@alu.uclm.es; Jaime.Campoy@uclm.es; Alfonso.Calera@uclm.es

\section{Abstract:}

The irrigated area cultivated with almond trees (Prunus dulcis) has doubled in Spain in the past 5 years. Almond is becoming a very extended tree crop in Spain, due to the high response of this crop to water used jointly with the likewise good market perspectives. Thus, almond is a viable alternative to traditional crops, such as cereals and other woody crops. However, the crop is expanding into waterscarce areas. In this manner, precise irrigation management tools are required to adequate the water applied to the actual crop requirements with suitable temporal and spatial resolutions. Adequate estimates of the net irrigation water requirements allow to improve the water use efficiency and therefore, achieving more profitable and sustainable management. Thus, time series of remote sensing satellite images allow to describe the spatial and temporal evolution of the canopy and estimate with reasonable accuracy the evolution of transpiration coefficient during the whole growing season using the wellrecognized relationships reported in the scientific literature.

This work aims at estimating the almond tree evapotranspiration and the net irrigation water requirements applying a Remote Sensing-based Soil Water Balance. This approach integrates basal crop coefficient $\left(\mathrm{K}_{\mathrm{cb}}\right)$ derived from time series of satellite images into the daily soil water balance at the root depth, which is widely explained in the FAO 56 manual. This methodology is well-documented in literature for other crops, although limited information is available for almond.

The study was realized in a drip irrigated almond commercial farm located in Abarán (province of Murcia), during the campaign 2019. The net irrigation water requirements estimated using the methodology proposed were assessed with regard to actual applied irrigation data provided by the farmer.

The results obtained in the present study reveal the potential of the methodology proposed to accurately estimate the net irrigation water requirements of almond tress during the study campaign. Moreover, the approach proposed was to able to capture differences of water requirements between the analyzed plots.

The operational application of this methodology will allow the farmer to know the actual crop water demand and adjust the water inputs to the crop water requirements. The information obtained is useful for making management decisions aimed at improving irrigation scheduling, developing controlled deficit irrigation (CDI) strategies and optimizing the management and use of water resources.

Keywords: NDVI ; almond tree ; irrigated ; satellite ; crop coefficient ; evapotranspiration 


\section{Introducción}

La actividad agraria es el sector que mayor consumo de agua demanda, por encima de los usos domésticos, industrial y de servicios. Sin embargo, la escasez de agua es el factor más limitante que condiciona el desarrollo de los cultivos y la producción de alimentos en muchas zonas del mundo.

En la actualidad, el cultivo del almendro (Prunus dulcis) se presenta como una alternativa rentable al cultivo de cereales y otros leñosos. España posee la mayor superficie dedicada a este cultivo en el mundo con 687225 ha, de la que el 84,7\% del área se maneja en condiciones de secano [1]. Sin embargo, la superficie dedicada al cultivo del almendro en regadío se ha duplicado en España en los últimos 5 años, debido a la alta respuesta del rendimiento de este cultivo a la cantidad de agua aplicada junto con su alta rentabilidad en la actual coyuntura de mercado.

Para afrontar el reto de optimizar los recursos hídricos en zonas con condiciones de escasez de agua es necesario el desarrollo y la aplicación de herramientas que permitan conocer la demanda de los recursos hídricos de los cultivos con la suficiente precisión, resolución espacial y temporal. Actualmente, la alta disponibilidad, frecuencia y resolución espacial de las imágenes multiespectrales de los satélites Sentinel 2A (S2A) y Sentinel 2B (S2B), pertenecientes al programa Copernicus de ESA, permiten obtener series temporales densas de imágenes capaces de describir de forma precisa el ciclo de crecimiento del cultivo.

De esta manera, las series temporales de imágenes NDVI de satélite constituyen una herramienta valiosa y operativa que permiten caracterizar la evolución temporal y espacial de los cultivos en tiempo real, y estimar con precisión diferentes parámetros biofísicos a lo largo del ciclo de crecimiento, como el coeficiente basal de cultivo $\left(\mathrm{K}_{\mathrm{cb}}\right)$, a través de relaciones robustas y ampliamente asentadas en la literatura científica. La determinación del $\mathrm{K}_{\mathrm{cb}}$ a través de medidas de reflectividad de la cubierta vegetal procedente de sensores remotos y su integración en el balance diario de agua en suelo, permite estimar de forma continua la evapotranspiración del cultivo [2] y sus necesidades de agua.

El objetivo general del presente trabajo es estimar la evapotranspiración del cultivo del almendro y sus necesidades de agua de riego mediante la implementación del modelo de balance diario de agua en el suelo explorado por las raíces descrito en el manual de FAO 56 [3] y asistido por teledetección. Esta información resulta relevante para ajustar las aplicaciones de riego a las necesidades reales del cultivo.

El estudio se ha realizado en una explotación de almendro con riego localizado situada en el término municipal de Abarán (provincia de Murcia) durante la campaña 2019. Las necesidades de agua de riego estimadas con el modelo propuesto son evaluadas frente a datos reales de riego aplicados por el agricultor. Además, para el desempeño de la metodología propuesta se han empleado series temporales de imágenes NDVI de alta resolución derivadas de los satélites S2A y S2B.

\section{Materiales y métodos}

- $\quad$ Zona de estudio

El estudio se ha realizado en la finca de Casablanca, que se localiza en la comarca Vega Alta del Segura, en el término municipal de Abarán (provincia de Murcia, ver Figura 1.

El clima en la zona de estudio es el Mediterráneo, caracterizado por una acusada variación estacional. De acuerdo a los datos obtenidos desde la estación agrometeorológica de Jumilla (Román) (latitud: $38^{\circ} 19^{\prime} 5^{\prime \prime} \mathrm{N}$; longitud: $1^{\circ} 19^{\prime} 32^{\prime \prime} \mathrm{O}$; altitud: $340 \mathrm{~m}$ ) procedente de la red SIAR (Servicio Integral de Asesoramiento al Regante), para el periodo de tiempo de 23 años (1998-2021) la temperatura media anual fue de $16,7^{\circ} \mathrm{C}$. Julio es el mes más cálido del año con una temperatura media mensual de $26,8^{\circ} \mathrm{C}$, en contrate enero es el mes más frío con una temperatura media de $8,2^{\circ} \mathrm{C}$. El 


\section{ACERYD}

CARTAGENA 2021

periodo medio libre de heladas está comprendido desde el 28 de marzo al 1 de diciembre, con una duración de 248 días. La precipitación media durante el mismo periodo fue de $328 \mathrm{~mm}$.

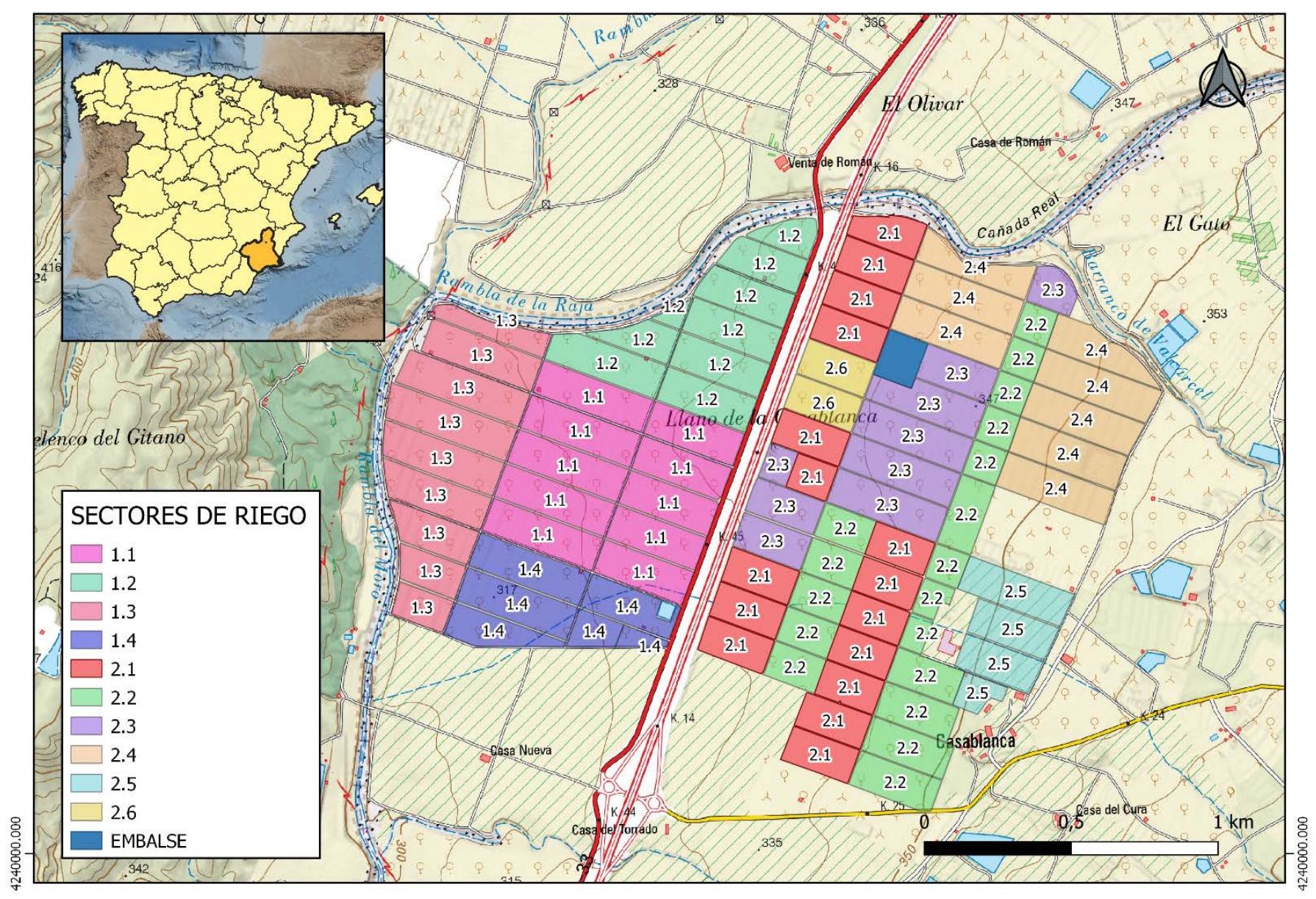

Figura 1. Localización de la zona de estudio, y distribución de los sectores de riego de la finca Casablanca (Abarán, Murcia).

Tabla 1. Cuadro descriptivo de los sectores.

\begin{tabular}{|c|c|c|c|c|}
\hline Código & Año & Variedad & $\begin{array}{c}\text { Marco } \\
\text { plantación }\end{array}$ & На \\
\hline $1.1 \_6 \times 6$ & 2012 & 33\%ANTOÑETA $66 \%$ FERRAGNES & $6 \times 6$ & 43.15 \\
\hline $1.25 \times 3$ & 1987 & 10\%CRISTOMORTO 30\%FERRADUEL 60\%FERRAGNES & $5 \times 3$ & 28.55 \\
\hline $1.3 \_5 \times 3$ & 1987 & 10\%CRISTOMORTO 30\%FERRADUEL 60\%FERRAGNES & $5 \times 4$ & 10.81 \\
\hline $1.3 \_5 \times 4$ & 1987 & 10\%CRISTOMORTO 30\%FERRADUEL 60\%FERRAGNES & $5 \times 3$ & 27.40 \\
\hline $1.4 \_5 \times 4$ & 1987 & 10\%CRISTOMORTO 30\%FERRADUEL 60\%FERRAGNES & $5 \times 4$ & 12.89 \\
\hline $1.4 \_6 \times 6$ & 2009 & 100\%ANTOÑETA & $6 \times 6$ & 6.11 \\
\hline $2.1 \_6 \times 6$ & 2009 & 100\%ANTOÑETA & $6 \times 6$ & 43.37 \\
\hline $2.2 \_6 \times 6$ & 2009 & $100 \%$ ANTOÑETA & $6 \times 6$ & 38.24 \\
\hline $2.3 \_6 \times 6$ & 2015 & 33\%ANTOÑETA 66\%FERRAGNES & $6 \times 6$ & 31.02 \\
\hline $2.4 \_6 \times 6$ & 2019 & $100 \%$ ANTOÑETA & $6 \times 6$ & 35.96 \\
\hline $2.6 \_5 \times 4$ & 1987 & 20\%CRISTOMORTO 40 FERRADUEL 40\%FERRAGNES & $5 \times 4$ & 5.97 \\
\hline
\end{tabular}


La explotación objeto de estudio tiene una superficie total de 440 hectáreas, de las cuáles 350 ha se dedican al cultivo del almendro en regadío y 90 ha al cultivo de cereales en secano. La finca cuenta con dos pozos y un embalse para el abastecimiento de agua de riego. Además, dispone de dos naves para el almacenamiento de la almendra tras la recolección.

En la Figura 1 se muestra la localización de la explotación objeto de estudio y la distribución de los sectores de riego. La finca dispone de 10 sectores de riego. Cada sector recibe una aplicación de agua dependiendo de sus características, principalmente el marco de plantación, y la aplicación de agua es homogénea dentro de cada sector. La Tabla 1 muestra las principales características de los sectores de riego (código, año de plantación, variedad cultivada, marco de plantación, superficie). El sector 2.5 no se incluye en el estudio al ser una plantación muy reciente realizada en el año 2020.

Las primeras plantaciones se hicieron en el año 1987; se diseñaron en un marco de plantación con calles de 5 metros y una separación entre árboles de 3 metros, siendo pioneros al mecanizar todo el proceso de recolección de la almendra a través del sistema americano, en el que la almendra se recoge barriendo el suelo. Este diseño todavía sigue presente en la explotación en los sectores 1.2 y parte del 1.3. También se diseñó con otro marco de plantación, separando un metro la separación entre árboles en los sectores 1.3, 1.4 y 2.6 siendo la separación entre árboles de 4 metros y la de las calles 5 metros.

En las nuevas plantaciones, realizadas a partir del 2009, con la aparición del sistema de recolección con paraguas invertido que consiguió mecanizar todo el proceso de la recolección, el marco de plantación ha sido a cinco de oros o tresbolillo irregular a 6 metros.

En lo que respecta al riego aplicado, el agricultor posee un registro diario de las horas de riego empleadas en cada sector, en la cual se ha basado nuestro estudio. A efectos de validación de las dosis aplicadas, se han realizado dos evaluaciones de riego en campo, en el sector 1.1 y 1.2, como representativos de cada uno de los diseños agronómicos existentes en la finca, con el objetivo de conocer la pluviometría media del sistema de goteros y la uniformidad de emisión. Los resultados obtenidos en esta evaluación muestran que la pluviometría de los emisores se acerca a la nominal, con un buen desempeño de la instalación.

Por último, el agricultor ha facilitado información en cuanto la profundidad del suelo según su experiencia en campo y también se ha realizado un análisis de suelo necesario para conocer el agua disponible, la capacidad de campo y el punto de marchitez en el perfil del suelo.

- $\quad$ El Modelo de balance de agua FAO 56 asistido mediante teledetección

El modelo de balance de agua descansa en el principio de conservación de la masa para el agua contenida en la capa de suelo explorado por las raíces del cultivo. Un modelo ampliamente utilizado es el que se describe en detalle en el manual FAO 56 [3], que utiliza un paso de tiempo diario y en el que la evapotranspiración del cultivo (ET) se calcula mediante el procedimiento ET $=\mathrm{K}_{\mathrm{c}}$. ETo, coeficiente de cultivo, $\mathrm{K}_{\mathrm{c}}$, multiplicado por la evapotranspiración de referencia, ETo. Una versión avanzada de FAO 56 es la que utiliza el coeficiente dual, en el que se desglosa el coeficiente de cultivo en un coeficiente de cultivo basal, $\mathrm{K}_{\mathrm{cb}}$, y un coeficiente de evaporación, $\mathrm{K}_{\mathrm{e}}$, lo que permite calcular por separado la componente de transpiración, $\mathrm{T}=\mathrm{K}_{\mathrm{cb}} \cdot \mathrm{ETo}$, y la componente de la evaporación del suelo desnudo, $\mathrm{E}=\mathrm{K}_{\mathrm{e}} \cdot \mathrm{ETo}$. 


\section{Congreso Nacional de Riegos CARTAGENA 2021}

Cuando el contenido de agua en el estrato de suelo explorado por las raíces cae por debajo de un cierto valor umbral el cultivo puede entrar en estrés hídrico. La aparición de estrés implica una reducción del ritmo al cual transpira el cultivo, debido al cierre de estomas por el insuficiente contenido de agua en suelo. En FAO 56 el estrés hídrico se modela mediante un parámetro denominado coeficiente de estrés hídrico, $\mathrm{K}_{\mathrm{s}}$, que tiene el valor de 1 en ausencia de estrés. En presencia de estrés, cuando el contenido de agua en suelo cae por debajo de un umbral que depende del cultivo, el valor de $\mathrm{K}_{\mathrm{s}}$ es menor que 1, y disminuye de forma proporcional a cómo disminuye el contenido de agua en suelo.

El modelo FAO 56 se denomina "asistido por teledetección" [4] cuando el coeficiente de cultivo basal se deriva de la serie temporal de imágenes de satélite que describen la evolución del cultivo. Esto se hace principalmente a través de su relación con los denominados índices de vegetación [5], que se calculan desde las imágenes multiespectrales. En este trabajo se utiliza la relación lineal, $\mathrm{K}_{\mathrm{cb}}=1.44 \cdot \mathrm{NDVI}-0.10$, obtenida sobre un cultivo de viña [6]. Dado que el modelo opera en paso de tiempo diario, los valores del NDVI son interpolados linealmente para obtener valores interpolados.

- $\quad \underline{\text { Suelo }}$

La Tabla 2 muestra el valor de las propiedades hídricas del suelo utilizados en este caso de estudio, teniendo en cuenta las características conocidas del suelo y analíticas disponibles.

Tabla 2.- Propiedades hídricas del suelo en el modelo FAO 56 asistido por satélite utilizado en este estudio.

\begin{tabular}{cccc}
\hline Parámetro & Valor & Unidad \\
\hline Profundidad & Franco arcillosa & $\mathrm{m}$ \\
Textura & & 0,346 & - \\
\cline { 1 - 1 } Capacidad de campo & 0,183 & $\mathrm{~m}^{3} / \mathrm{m}^{3}$ \\
\cline { 1 - 1 } Marchitez permanente & 200 & $\mathrm{~mm}$ \\
\hline Agua disponible total en la zona radicular (ADT) & & $\mathrm{mm}$ \\
\hline
\end{tabular}

- $\quad$ Imágenes de satélite

Para el año 2019, que es del que se muestran los resultados en este trabajo, se han procesado un total de 24 imágenes libres de nubes, adquiridas por los satélites gemelos Sentinel 2A y Sentinel 2B, con una resolución espacial de $10 \mathrm{~m} \times 10 \mathrm{~m}$. Estas imágenes han sido procesadas y normalizadas para obtener la reflectividad en superficie y calcular de ellas el NDVI, de acuerdo a la metodología utilizada por la Sección de Teledetección y SIG del Instituto de Desarrollo Regional en la Universidad de Castilla-La Mancha

Finalmente se ha calculado el valor promedio de NDVI para cada sector en cada una de las imágenes disponibles; este valor promedio se obtiene mediante la realización de una operación SIG de agregación espacial de los valores de NDVI correspondientes a todos los píxeles de cada uno de los sectores, aplicando un "buffer" que elimine aquellos pixeles cuyo centro geométrico se encuentre a menos de $7 \mathrm{~m}$ de la línea que delimita el sector.

Operando de la misma forma, se han analizado los años 2020 y 2021, aunque los resultados no se muestran en el presente estudio.

Una cuestión importante es si el valor del NDVI se debe a la cubierta de los árboles o pudiera ser alterado por la presencia de arvenses; en la explotación en estudio las malas hierbas se controlan muy cuidadosamente, como se pudo comprobar en las visitas a campo, aunque es inevitable que 
pueda incrementar levemente este valor en los meses de primavera u otoño después de las lluvias. Se asume pues que el valor del NDVI corresponde esencialmente a la cobertura vegetal verde de los árboles.

\section{- $\quad$ Meteorología}

Los datos meteorológicos utilizados, Evapotranspiración de referencia $\left(\mathrm{ET}_{\mathrm{o}}\right)$ y precipitación, se obtienen a escala diaria desde la estación agrometeorológica procedente de la red SIAR (Servicio Integral de Asesoramiento al Regante) más cercana a la finca (MU125, Jumilla-Román, Murcia).

\section{Resultados y discusión}

\section{Patrón temporal de la evolución del NDVI}

La Figura 2 muestra la evolución temporal del NDVI correspondientes al año 2019, para cada uno de los 11 sectores, en la que se han indicado las fechas de floración y cosecha. El patrón temporal el refleja un crecimiento rápido del NDVI después de la floración, crecimiento que alcanza un máximo en abril, decreciendo suavemente hasta la senescencia y pérdida de hoja.

En la gráfica se representa el periodo vegetativo de 2019, donde se puede apreciar una tendencia con valores más altos en los sectores con los marcos de plantaciones más densos con 667 y 500 árboles por hectárea (1.4_5x4,1.2_5x3, 1.3_5x3, 1.3_5x4 y 2.6_5x4), alcanzando valores de NDVI de 0,64 para el mes de abril. Siendo también el valor más alto para el resto de sectores el mes de abril con densidades de 248 árboles por hectárea (1.1_6x6, 1.4_6x6, 2.1_6x6, 2.2_6x6, 2.3_6x6 y 2.4_6x6) con un valor de NDVI de 0.53 . También se puede apreciar las diferencias del sector $2.4 \_6 \times 6$, cultivo implantado ese mismo año, con el resto de sectores o el sector 2.3_6x6 con 4 años de vida, donde todavía no ha alcanzado su máximo desarrollo.

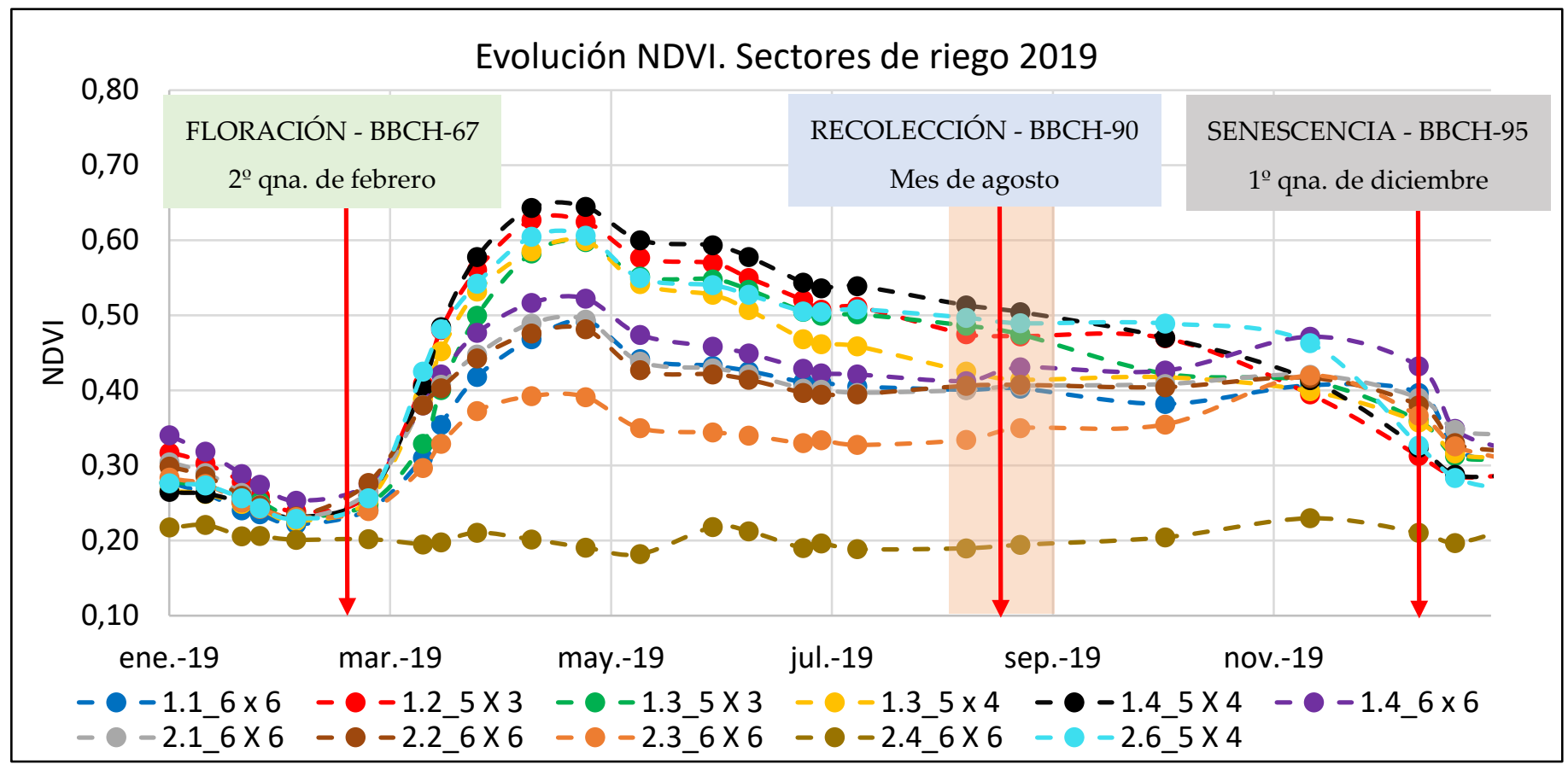

Figura 2. Evolución temporal NDVI. Serie temporal de imágenes de satélite (S2A, S2B), 2019. 


\section{Congreso Nacional de Riegos CARTAGENA 2021}

Las diferencias de los patrones temporales entre los sectores muestran que las series temporales de imágenes de satélites son capaces de capturar las diferencias en el desarrollo y en el crecimiento del cultivo entre los distintos sectores de riego.

\section{Balance de agua}

El balance de agua ha permitido calcular las necesidades de agua de riego totales en la campaña considerando un manejo en ausencia de estrés, lo que se ha comparado con la aplicación de agua por parte del agricultor. Los resultados de esta comparación se muestran en la Figura 3.

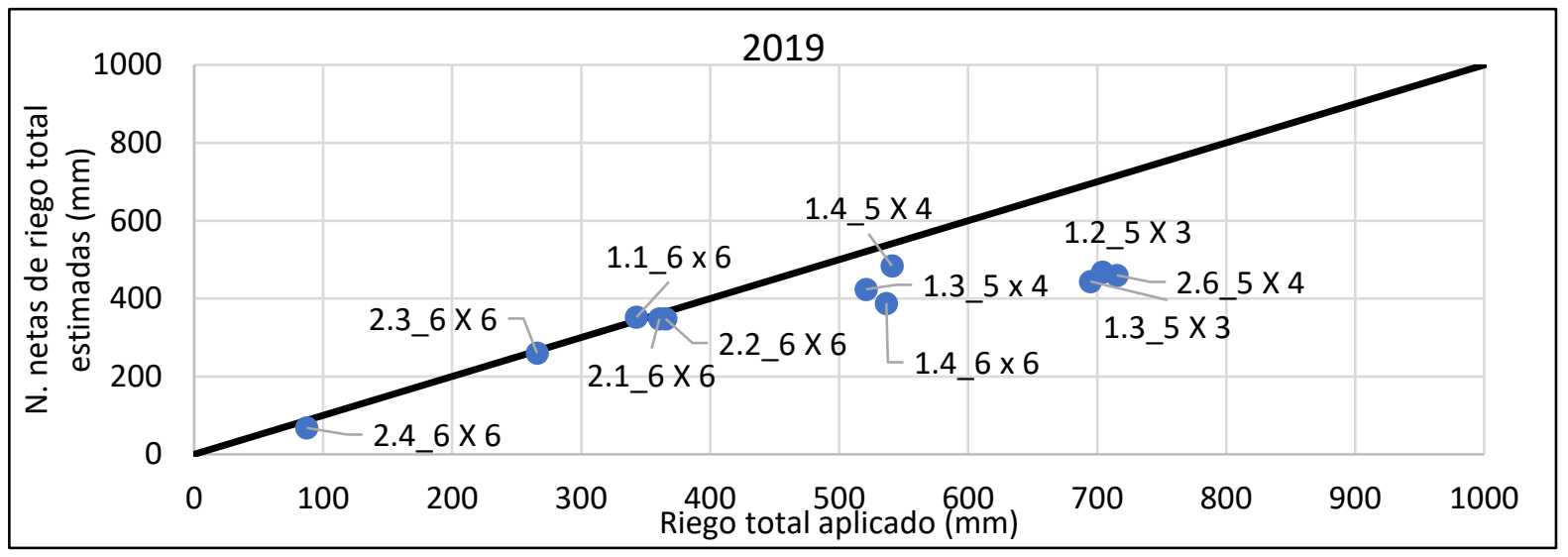

Figura 3. Necesidades netas de riego total estimadas vs riego total aplicado en sectores de riego, año 2019.

En la Figura 3 se comparan los datos de los riegos aportados por el agricultor y los riegos estimados por el modelo, para el año 2019 en todos los sectores de riego. Tal y como se puede apreciar, las necesidades netas de riego totales estimadas con la metodología propuesta son muy similares al riego total aportado por el agricultor en la mayoría de los sectores de riego $\left(1.3 \_5 \times 4,1.4 \_6 \times 6,1.4 \_5 \times 4,1.1 \_6 \times 6\right.$, $2.2 \_6 \times 6,2.1 \_6 \times 6,2.3 \_6 \times 6$ y 2.4_6x6). Sin embargo, se distinguen claras discrepancias entre las estimaciones y las aplicaciones de riego totales en algunos sectores (1.2_5x3, 1.3_5x3 y 2.6_5x4). En estos sectores que coinciden con los marcos de plantación de mayor densidad, el modelo estima unas necesidades totales menores a las aportadas por el agricultor.

Un paso adicional a este análisis es considerar la distribución temporal de las necesidades de agua de riego. Se ha elegido para este análisis el sector 1.2 como representativo de los sectores que presentan una mayor diferencia entre las cuantías totales de agua aplicada y las necesidades estimadas, que son aquellos que presentan también una mayor cobertura vegetal, con el marco de $5 \mathrm{~m} \times 3 \mathrm{~m}$ y 667 árboles/ha.

Para ello se ha realizado de nuevo el balance de agua utilizando las aplicaciones de agua realizadas por el agricultor como un dato de entrada adicional al modelo. En este caso el modelo permite estimar el contenido de agua en el suelo, de acuerdo con el resto de parámetros utilizados y que se han descrito anteriormente.

En la Figura 4 se representa la estimación del agotamiento del agua en el suelo, definido como la diferencia entre la capacidad total de agua en suelo disponible para las plantas $(200 \mathrm{~mm})$ menos el contenido de agua en suelo en cada día del ciclo de cultivo. El modelo permite estimar también la percolación, que se define como el agua que sale de la capa explorada por las raíces hacia capas más profundas, lo que sucede en determinados momentos debida a la aparición de precipitaciones con el perfil del suelo con un alto contenido de agua. La línea de $80 \mathrm{~mm}$, esto es el $40 \%$ de la capacidad total, corresponde al umbral de agua fácilmente utilizable, de acuerdo a lo indicado en FAO 56 para el almendro. 


\section{Congreso Nacional de Riegos CARTAGENA 2021}

En el caso de este sector se da un tanto la paradoja de que se aplica un mayor aporte de agua por el agricultor, $668 \mathrm{~mm}$, que la cuantía estimada como óptimo, $469 \mathrm{~mm}$, y aun así parece puede producirse algún estrés hídrico en algún momento del ciclo.

La Figura 5 muestra la diferente distribución temporal de las recomendaciones de agua de riego que el modelo estima como óptimas, al imponerse la condición que el coeficiente de estrés se mantenga con un valor alrededor de 1 . Asimismo, se le impone la condición de una dosis máxima de $6 \mathrm{~mm} /$ día, que es la capacidad nominal del sistema de riego.

La diferencia entre las necesidades estimadas y el agua realmente aplicada se explica fundamentalmente por una mejor gestión del agua en el suelo que evita posibles percolaciones en la primavera. Obviamente el modelo no contempla aquellas prácticas de manejo ligadas a la fertilización ni a prácticas de limpieza de tuberías, etc., que tienen una dinámica propia, no ligada estrictamente a satisfacer las necesidades de agua.

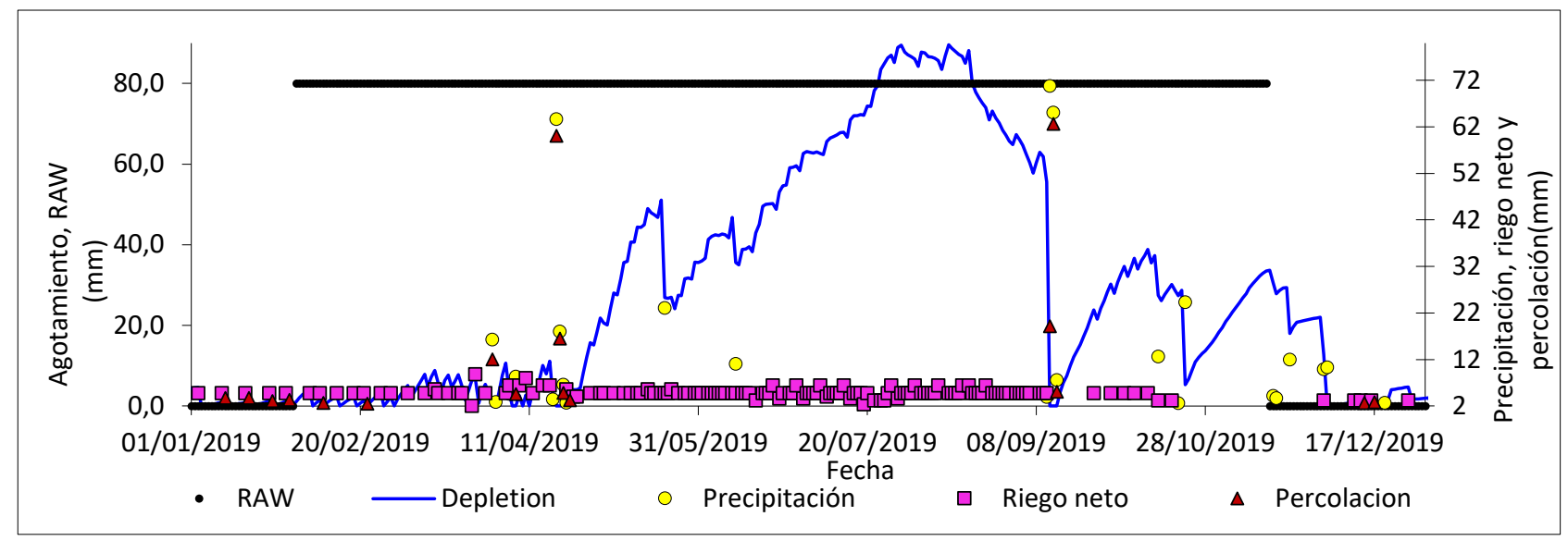

Figura 4. Agotamiento en la zona radicular calculado por el método del coeficiente dual para el sector 1.2, junto con al riego aplicado por el agricultor y la precipitación registrada en la estación meteorológica de Jumilla-Román (Murcia)

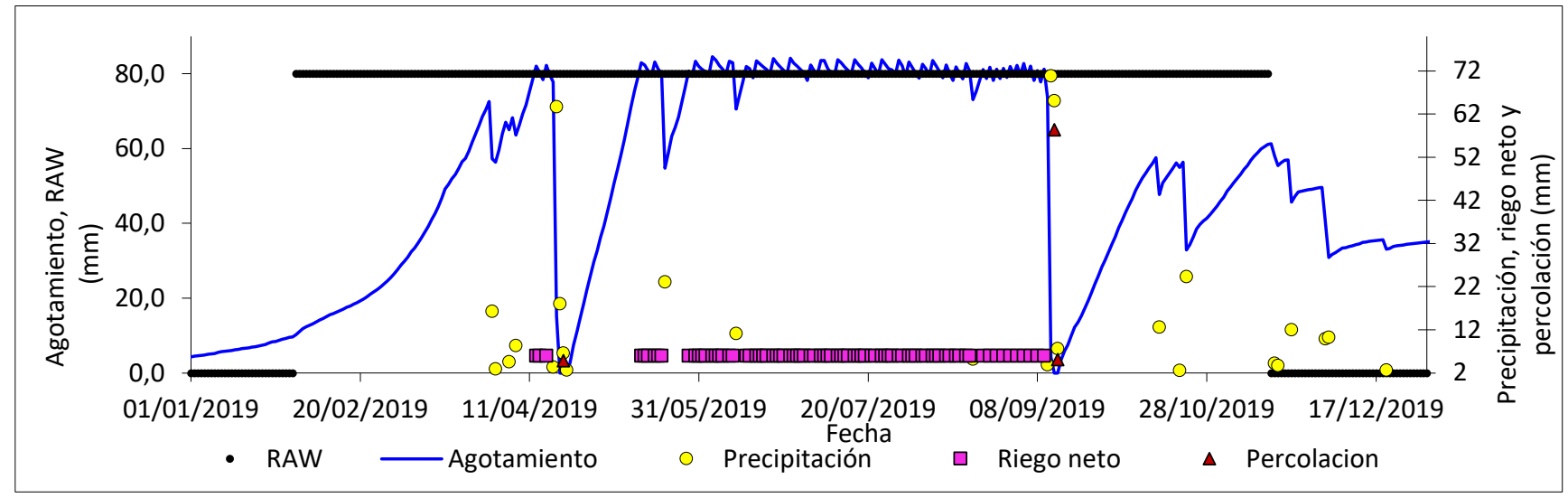

Figura 5. Agotamiento en la zona radicular calculado por el método del coeficiente dual para el sector 1.2, junto con al riego estimado por el modelo y la precipitación registrada en la estación meteorológica de Jumilla-Román (Murcia)

\section{Conclusiones}

El balance agua FAO 56 asistido por satélite, en el que el coeficiente de cultivo basal se deriva de imágenes multiespectrales, es en la actualidad una herramienta operativa para una aproximación a la 
determinación de las necesidades de agua del almendro, tanto en la cuantía total de agua a aplicar durante el ciclo de crecimiento, como en cuanto a determinar cuándo y cuánto regar bajo las condiciones establecidas por el sistema de riego y cuantía de agua disponible.

Desde el año 2017 hasta el presente se tiene acceso libre y gratuito, prácticamente en tiempo real, a las imágenes de los satélites gemelos Sentinel 2A y Sentinel 2B, del programa Copernicus de la Comisión Europea. Las imágenes ofrecen una resolución espacial de tamaño de pixel de $10 \mathrm{~m} \times 10 \mathrm{~m}$, y la constelación de satélites posibilita un período de revisita de 3 a 5 días, lo que permite disponer de suficientes imágenes libres de nubes para describir la evolución del cultivo con una alta frecuencia temporal.

Operando con estas imágenes, el modelo de balance de agua FAO 56 asistido mediante teledetección proporciona unas estimaciones de necesidades de agua de riego que se corresponden razonablemente bien con el riego total aplicado por el agricultor.

Sin embargo, la distribución temporal de las aportaciones de agua de riego admite potencial de mejora, que puede ser analizado mediante las herramientas descritas en este trabajo. En este sentido se ha puesto en marcha un proceso de colaboración con el agricultor para integrar en el modelo las condiciones de manejo del agua específicas en cuanto a la disponibilidad de agua y objetivos agronómicos, al objeto de maximizar el agua disponible.

\section{Referencias}

1. MAPA, 2020. Anuario de estadística, 2019, 2020. Ministerio de Agricultura, Pesca y Alimentación, Madrid, España.

2. Neale, C. M. U., Bausch, W. C., \& Heermann, D. F. (1989). Development of reflectance-based crop coefficients for corn. Transactions of the American Society of Agricultural Engineers, 32(6), 1891-1899.

3. Allen, R. G., Raes, D., \& Smith, M. (1998). Crop Evapotranspiration: Guidelines for Computing Crop Requirements. In Irrig. Drain. Pap. No. 56, FAO, Rome, Italy.

4. Calera, A., Campos, I., Osann, A., D’Urso, G., \& Menenti, M. (2017). Remote sensing for crop water management: From ET modelling to services for the end users. Sensors, 17(5), 1-25.

5. Pôças, I., Calera, A., Campos, I., \& Cunha, M. (2020). Remote sensing for estimating and mapping single and basal crop coefficientes: A review on spectral vegetation indices approaches. Agricultural Water Management, 233(December 2019), 106081.

6. Campos, I., Neale, C. M. U., Calera, A., Balbontín, C., \& González-Piqueras, J. (2010). Assessing satellite-based basal crop coefficients for irrigated grapes (Vitis vinifera L.). Agricultural Water Management, 98(1), 45-54. 